\title{
Mental health in Argentina: interdisciplinary program based in community care
}

\author{
Saguinetti Carlos, Marin Gustavo H*, Herrera Natalia, Molteni Oscar, Milito Sofia, Molinero Cinthia, Posse Ana, Riquelme Jesica, Rodriguez \\ Manuel, Amadeo Jimena, Belauzaran Lucia, Cejas Natalia, Gonzalez Olivi Matías, Kess Gabriela, López Noelia and Maestropiedra Marcelo \\ Subsecretaria de Adicciones, Ministerio de Salud de la Provincia de Buenos Aires, Argentina
}

\begin{abstract} practices are inefficient and outdated. interdisciplinary approaches for patients affected by mental illness or by drug addiction.

\section{Introduction}

During the last decades of the $20^{\text {th }}$ century, many countries underwent a process of change about the approach to mental health care. This process attempts to strengthen a community-based care model for people with mental disorders and problematic substance abuse substituting the repressive practices of isolation in mental health facilities [1]. Mental health and addiction care are closely related to social, political and economical determinants. In Argentina as well as in many other countries in Latin America, strategies for mental health care changed according to the period of the history of those lands. In dictatorial and neoliberal political periods of Argentina, mental health treatment and assistance models were based in institutionalized isolation practices with the segregation and exclusion of people with mental illness or problematic substance abuse.
\end{abstract}

Mental health and drug addiction problems are closely related to social, political and economical determinants. Assistance models based in institutionalized isolation

Objective: To demonstrate the impact of a domiciliary care program called Community Link Interdisciplinary Regional Program (PRIEC) based on community and

Methods: 2 groups of patients, one included in PRIEC program and the other (control group CG) was treated in usual way.

Results: After 12 months of program, $92.6 \%$ of the patients considered themselves satisfied with the program, the period from first court admission to medical care was reduced in 69\%; treatment adherence was $78.2 \%$ (34.4\% in CG) p 0.001; hospital re-admission was only 18.3\% (56.7\% CG) p 0.003.

Conclusion: treatment of mental diseases or drug abuse problems based in community and interdisciplinary approaches demonstrated to be a more efficient strategy in terms of latency for medical care, treatment's dropout rate, and patient's satisfaction than isolation of these patients during residential treatment in mental hospitals.

International human rights and mental health standards as well as the Argentine National Law of Mental Health No 26657 enacted in 2010, and the new Argentine Civil Code that provides a legal framework to promote the implementation of community-based practices in mental health service systems and a different conceptualization of mental disorders $[2,3]$. This new paradigm recognizes several high-complexity problems, which require new inter-disciplinary and inter-sectoral assistance practices based on a global new approach.

Different life styles produce disorders and social determinants that impact on the health of the population [4]. Over the last decades, Argentina has gone through a political context that allowed broadening the rights of the most vulnerable people in the country [5]. This group includes people with mental disorders and problematic substance use, whose care has become a right that National government has to guarantee. It is within this framework that medical-hegemonic practices has been reviewing and substituted by inclusive practices that guarantee the rights of those in need [6,7].

Both National Law of Mental Health and Addictions No 26657 and State Law No. 14580 consider the mental health as a process determined by historical, socio-economical, cultural, biological and psychological components, and include all addictions as health problems. This approach recognizes mentally ill people have the right to be treated forcing governments to provide such care by law $[8,9]$.

Psychosocial problems and needs of patients with mental and substance abuse disorders require flexible intervention tools, which are close to their reality and their families/referents who are key actors in the care process and guarantee continuity of the treatments [10].

Due to difficulties presented by mental health disorders and problematic substance use, it is necessary to establish approach strategies based on inter-sectoral, global and interdisciplinary actions that express the patients' right to the best health care available. This implies treating them with respect and dignity, according to the current highest ethical, technical and humane standards, taking into account the right of gratuitousness, accessibility and territoriality.

In this order, a domiciliary mental health and addiction

Correspondence to: Prof. Dr. Gustavo Marin, National University of La Plata, Argentina. Calle 60 y 120, - 1900- La Plata, Argentina, Tel/Fax: 54-221-4216932; E-mail: gmarin2009@gmail.com

Key words: mental health, drug addiction, treatment, community

Received: December 20, 2015; Accepted: February 01, 2016; Published: February 05, 2016 
agency program (PRIEC) was created based on community and interdisciplinary approaches for patients affected by mental illness or by drug addiction prosecuted or who have been taken to court on trial procedure. The aim of the program is to reduce the gaps between demand and resources, limiting the admission barriers, the time spent in mental health institutions and facilitating the patients' re-entry into the community.

\section{Method}

\section{Study type: Intervention study.} 2015.

Period: The study took place from $1^{\text {st }}$ of January 2014 to $30^{\text {th }}$ June

Patients: The study included patients 18 years of age and older, with mental disorders and/or with substance abuse (DSM-V diagnosis), who have mostly been taken to court (Region XI). All these patients were invited to join the intervention program.

Another historically group of patients (control group) with the same average age and diagnosis, were taken into consideration for the analysis in order to compare these patients with the intervention group.

Inclusion criteria: Patients 18 years of age and older; admission to a court, recommendation to treatment.

Exclusion criteria: Patients that refused to be included in the PRIEC program or patients that judges refused to allow them to join the program.

Intervention: Judicialization or criminalization of health's situation is a very common practice that presents several essential factors. In this sense, the study proposed an intervention based on a program called PRIEC which is a regional tool that operates as a coordinating program between state and municipal health providers from the Province of Buenos Aires. Once a patient has its first court admission, the program is then activated. Health's providers are organized in order to coordinate actions to assure a fast continuous and integrated health care of that patient including different disciplines, sectors and levels of assistance. An active family and community participation in patient's follow-up process is guaranteed. These characteristics are the bases of the change of paradigm "from a hospitalization-based model to a community-based model".

The following schedule was designed to implement the program:

$\checkmark$ Formation of working teams

$\checkmark$ Training of the teams.

$\checkmark$ Administrative order of the records and communication of the program

$\checkmark$ Reception of demands and requests for intervention

$\checkmark$ Coordinator team meetings

$\checkmark$ Intervention team meetings

$\checkmark$ Link interventions, assignment of treatments

$\checkmark$ Decentralization of the requests for intervention

$\checkmark$ Inclusion of health providers to care networks

PRIEC also included global and interdisciplinary evaluation of the patients. This action took place either in the PRIEC head office or at the patient's home, according to patient's status.
After this first evaluation, the initial strategy for the treatment is proposed, according to the environment, the local network, the neighborhood, the place of residency and the patient's features. The distinct characteristic of this program is a home-based care practice adapted to each patient.

Variables: age and sex of the patients, court or judicial office, time from court admission to access to health's care; treatment adherence; re-admission because disease worsening.

Statistical analysis: variables obtained from both groups were submitted to statistical analysis using arithmetic mean, Student's ' $t$ ' test of correlation to compare results from both groups. p-values of $<0.05$ were considered to be statistically significant.

\section{Results}

During the period of study, 629 patients were included in legal court procedures and admitted as oppose to PRIEC program. Data from this group was compared with a Control group (CG) composed by 630 patients with legal cases during the same period that underwent classical care procedures.

$84.7 \%$ of the patients who were admitted in PRIEC program and $85.5 \%$ of the patients considered for the control group were males.

$85.8 \%$ of the PRIEC patients reported that they were previously assisted by mental health care and/or addiction teams from the State health care system (85.7\%) did so in the control group).

$75.6 \%$ of patients from the PRIEC group (and $71.8 \%$ from the control group) reported that they had been admitted in mental health facilities in the last 48 months; $76.7 \%$ from PRIEC and 73.6\% from Control group patients had received long term treatments and $84.4 \%$ PRIEC vs. $80.3 \%$ CG attended more than 10 different consultation services, however for $95.2 \%$ and $97.3 \%$ of those patients respectively, these actions were not enough were not enough to avoid patient's relapses.

98.4\% of PRIEC and $96.9 \%$ of CG patients expressed dissatisfied with the health care service they received before the program. This dissatisfaction was due to the location of the health service $(67.4 \%$ vs. 59.3\% CG); the period of consultation was considered too short $(84.2 \%$ vs. $80.1 \%)$ and because they felt discriminated with health care provided by the health system $(89.3 \% v s .92 .3 \%)$. All results mentioned so far for both groups lack of statistical signification.

After 12 months in the PRIEC program, or in control group patients were asked to answer a survey to determine their degree of satisfaction, and about their health and legal process. $92.6 \%$ of the PRIEC patients were satisfied with the PRIEC program, the time from last court admission to health's attention was reduced in 69\% (from 10 months to 3 weeks); treatment adherence was $78.2 \%$ (compared to $34.4 \%$ of CG) p 0.001 ; re-admission because disease worsening was only $18.3 \%$ during the study period $(56.7 \%$ in patients belonging to control group) p 0.003 .

\section{Discussion}

Results of the study allow us to think about the need of strengthen and promoting home-based care practice. From January 2014 to June 2015, a total of 629 individuals, who had been taken to court, were included in the research study and compared with a control group that followed the normal health care. Before the implementation of the program, individuals who broke the law have long waiting periods 
until they manage to obtain the formalized admission to a mental health facility for his/her evaluation. This fact fosters the "in-out" effect and has not proved to be effective. When the individual is a potential danger to the society, courts indicate the direct delivery of the person to the regional neuropsychiatric hospital to be included in a long term residential treatment. Clearly this type of response is far from meeting the needs of the population or promoting the convenient consultation to avoid unnecessary admissions in psychiatric facilities.

The PRIEC program allowed us to work with people who due to different causes, could not attend ambulatory consulting services, who abandoned treatment or need intensive support throughout his/ her treatment. Practices of domiciliary care have been consolidated when family support is provided and the working team supervises the pharmacological treatment. This type of alternative therapeutic interventions is a useful tool that favors the adaptation and inclusion of patients in the community by fostering social relationships. Working with the families and community referents was essential to reduce the level of hospital's admissions in terms of frequency and periods of time.

Unnecessary admissions and long-term stays in mental facilities have been reduced by applying the PRIEC program. Network construction has passed through all the necessary moments until it was finally obtained excellent results. Only $7.31 \%$ out of the total number of individuals surveyed in PRIEC were admitted in a mental health facility. These reduction of hospital admissions, led us to believe that many of those legal suits for patients admissions in mental institutions might be unnecessary or liable to be treated as outpatient. The intervention strategies of the PRIEC program have reached the goal of working on the need of providing a convenient and appropriate assistance with an inter-sectoral and community approach.

Argentina has a great fragmentation in its health system and a lack of knowledge about the available resources in Buenos Aires State. There is no doubt that change in the paradigms demands time and transformations in health system. Institutional admission of patients with mental disorders and problematic substance usage should be reconsidered. Mental health teams should analyse the essential fundaments of their practices, society characteristics, the addiction problem and the different substances used by the patients.
The challenge is to consider all these aspects in order to consolidate a community-based mental health model, which will enhance intersectoral and community participation and work on the integration of the mental health actions into general health actions, where social perspective is transversal to health practices.

\section{Conclusions}

Mental or drug abuse patients treated by home-community based care practices were able to improved their access to health care, reduced treatment's dropout rates, and increased the overall satisfaction with the treatment than those patients treated by their isolation in mental hospitals.

\section{References}

1. Bang C (2014) Community Strategies for Health Promotion: Building networks for facing psicological and social problems. In Psicoperspectivas. Individuo y Sociedad 13

2. National Mental Health Law-Ley Nacional de Salud Mental- (2010). Ley N ${ }^{\circ} 26.657$. Right for Mental Health Protection.

3. State Law 14580 (2010) Formal State Adhesion to National Law about Mental Health

4. Gallende E (1997) Actual situation of Mental Health in Argentina. Journal of Health Problem and Debate-Revistasalud, problema y debate 17: 10-15.

5. Gallende (1990) Psicoanalysis and Mental Health. Critical approach of PsiquiatryRationallity. Buenos Aires: Ed. Paidós.

6. Bang C (2010) Strategies for Community Mental Health promotion: An approach from the complexity paradigm. Faculty of Psicology, Buenos Aires National UniversityUBA (Ed.), Memories from the II International Congress on Research and Practice in Professional Psicology (Tomo 3) (pp. 242-245). Buenos Aires: Faculty of Psicology, UBA.

7. Rovere M (1999) Networks in Health: The new Paradigm to face the Community. Redes En Salud; Un Nuevo Paradigma para el abordaje de las organizaciones y la comunidad, Rosario: Ed. Secretary of Public Health/AMR, Lazarte Institut.

8. Rotelli F (2014) Living without Mental Hospitals. The experience of Trieste. Ed. Topía. Documents for XXI Century-Colección Fichas para el Siglo XXI; 34-41.

9. Stolkiner A, Ardila S (2012) Concepts in Practice of Mental Health: Considering Social Medicine/Salud Colectivalatinoamericana. Vertex. Revista Argentina de Psiquiatría 23: 52-56.

10. Jairnilson Silva Paim (2011) Challenge for Community Health in XXI Century. Desafíos para la salud colectiva en el Siglo XXI. Ed. 2011.BsAs.

Copyright: (C2016 Carlos S. This is an open-access article distributed under the terms of the Creative Commons Attribution License, which permits unrestricted use, distribution, and reproduction in any medium, provided the original author and source are credited. 